\title{
Trend and dynamic of chlorophyll-a concentration over the Arabian Gulf: A long-term study using MODIS data (2004-2019)
}

\author{
Jasem A Albanai \\ Marine Monitoring Section, Water Quality Monitoring Department, Environmental Public Authority, Kuwait \\ Corresponding Author: Albanay.com@gmail.com
}

$\begin{array}{ll}\text { Submitted } & : 17 / 11 / 2020 \\ \text { Revised } & : 07 / 03 / 2021 \\ \text { Accepted } & : 28 / 03 / 2021\end{array}$

\begin{abstract}
Chlorophyll- $a$ concentration in water is an indicator of phytoplankton density, which in turn is crucial, as it represents the base of the ecological life in seas and oceans. Any increase or decrease in the number of phytoplankton may contribute to disruption to the ecological cycle in the seawater. The density of phytoplankton is also an important indicator of water quality. Traditionally, water samples are collected in the field and analysed in the laboratory to find the density of phytoplankton in a specified amount of water. Recently, remote sensing has led to the development of advanced and remote methods to detect phytoplankton density, chiefly by extracting near-surface chlorophyll- $a$ concentrations. In this study, MODIS (Aqua) Level 3 data (64 images) were used to extract average chlorophyll- $a$ concentration at time points from 2004 to 2019 (over 16 years) for the Arabian Gulf, where the Level 2 (11 images) data were used to determine the accuracy of the estimated values via MODIS (Aqua) using field data taken from the waters of the State of Kuwait (25 points). The results showed good accuracy for MODIS (RMSE $= \pm 1.066$ ), and they also show that the temporal seasonal averages change in annual-cycles and that the trend decreased from 2004 to 2019 , by about $0.7 \mathrm{mg} / \mathrm{m}^{-3}$.
\end{abstract}

Keywords: Arabian / persian gulf; Kuwait; MODIS; Chlorophyll- $a$; Coastal engineering.

\section{INTRODUCTION}

The water quality of the hydrosphere is determined by measuring a set of its characteristics, such as sea surface temperature, salinity, dissolved oxygen, chlorophyll- $a$ concentration, and turbidity. The concentration of chlorophyll$a$ is an indication of the phytoplankton density in water (Muller-Karger, Hu, Andréfouët, Varela, \& Thunell, 2005), with phytoplankton being the basis of ecological life in seas and oceans. There are many methods of monitoring water quality. Traditionally, it relies on field measurements to find out the spatial distribution, and subsequently using statistical analysis methods to identify the temporal pattern and dynamic. Recently, remote sensing methods have been increasingly used to monitor water quality through the interactions of electromagnetic radiation with the water surface. Remote sensing instruments have several advantages that make it an important method for studying and 
monitoring the earth. The wide spatial coverage and archives provided by the satellites are combined to make it a useful tool to save time and effort.

Satellites and sensors vary in their characteristics and features. Some of them have high temporal resolution and moderate spatial resolution, such as MODIS spectrometer, while others offer higher spatial resolution and lower temporal resolution, such as Landsat satellites. The choice of the satellite and sensor depends on several factors, such as the size of the study area, the goals of the study, and the spectral bands covered by the satellite. The moderateresolution sensors launched by NASA, such as MODIS and VIIRS, are among the most frequently used in the study of near-surface chlorophyll- $a$ concentration, due to the availability of their data in the form of products extracted from the relationship between field measurements and the spectral bands of the sensor, such as near-surface chlorophyll- $a$ and sea surface temperature products. These products are characterized by high temporal resolution up to approximately one day, and they contain a huge archive that extends from the end of the last century to the present day. On the other hand, some limitations can be found for these sensors, for example, the moderate spatial resolution and weak spatial coverage of marginal seas such as the Arabian Gulf.

Despite the importance of remote sensing methods in measuring water quality and chlorophyll- $a$ concentration, a relatively limited number of studies have used satellite data to study the levels of chlorophyll- $a$ in the Arabian Gulf. This is chiefly due to several reasons related to the lack of quality in situ data, the dust storms that limit the usefulness of optical remote sensing (Al-Naimi, Raitsos, Ben-Hamadou, \& Soliman, 2017; Nezlin, Polikarpov, Al-Yamani, Subba Rao, \& Ignatov, 2010; Zhao \& Ghedira, 2014), and the weak spatial coverage of marginal seas such as the Arabian Gulf by the moderate spatial resolution sensors. Many studies have dealt with the marine environment of the Arabian Gulf in terms of general circulation and bathymetry (Brewer \& Dyrssen, 1985; Nezlin et al., 2010; Reynolds, 1993; Sheppard et al., 2010). The Gulf is relatively shallow and contains a counter-clockwise cyclical flow of water. Nezlin, Polikarpov \& Al-Yamani (2007) divided the Arabian Gulf into several subregions based on Reynolds' (1993) study of the Gulf's properties. Other studies analyzed the concentration of chlorophyll- $a$ in the Gulf and found that the concentration increases near coastal areas, as compared to the case in open and deep seas (Nezlin et al., 2007). The concentration of chlorophyll- $a$ is estimated to range from 0.01 to $10 \mathrm{mg} / \mathrm{m}^{-3}$ in the open water of the Arabian Gulf (Sheppard et al., 2010), whereas it reaches as much as 55.4 to $4525 \mathrm{mg} / \mathrm{m}^{-3}$ in abnormal conditions in the northwest of the Gulf (Al-Yamani, Saburova, \& Polikarpov, 2012). Some studies have dealt with the temporal analysis of chlorophyll concentration, such as Moradi \& Kabiri (2015), while other studies measured the accuracy of satellite readings across field data and found a positive correlation (Al-Naimi et al., 2017). However, this study aims to show the long-term temporal distribution of chlorophyll- $a$ concentration over the Arabian Gulf.

\section{MATERIAL \& METHODS}

\section{Study Area}

The Arabian Gulf (or the Persian Gulf, as it is sometimes called) is marginal water connected to the Arabian Sea by the Strait of Hormuz (Fig. 1). The Arabian Sea is part of the Indian Ocean, located specifically in the northern part of the ocean. The Arabian Gulf is located between $23.5^{\circ}$ and $30.05^{\circ}$ North and $47.5^{\circ}$ and $56.4^{\circ}$ East. The gulf has a subtropical hyperarid climate (Al-Yamani, Bishop, Ramadhan, Al-Husaini, \& Al-Ghadban, 2004) and is surrounded by desert lands. Due to the hydrometeorological conditions of the Gulf region, the sea surface temperature is relatively high, where it reaches a maximum of roughly $36{ }^{\circ} \mathrm{C}$ and a minimum of $14{ }^{\circ} \mathrm{C}$, and the salinity concentration ranges from about 35 to 70 PSU (Al-Naimi et al., 2017; Polikarpov, Al-Yamani, \& Saburova, 2019). The Gulf is relatively shallow, with the deepest point reaching just over 100 meters; its average depth is about 35 meters. The Gulf's total water volume is about $6000 \mathrm{~km}^{3}$ (Moradi \& Kabiri, 2015). The Gulf has a length and width (range) of approximately 990 and 56-338 km, respectively, and covers a total area of $240,000 \mathrm{~km}^{2}$ (Pokavanich et al., 2014). The water circulation consists of discharges from the Strait of Hormuz, and the Tigris and Euphrates rivers, which flow into the 
northern Arabian Gulf (Shatt al-Arab). The Arabian Gulf is of great economic importance due to the activity of international oil movement through the Strait of Hormuz, in addition to its wealth of fish, due to its location to the south of the Tigris and Euphrates rivers. These rivers are the main source of fish in the Gulf.

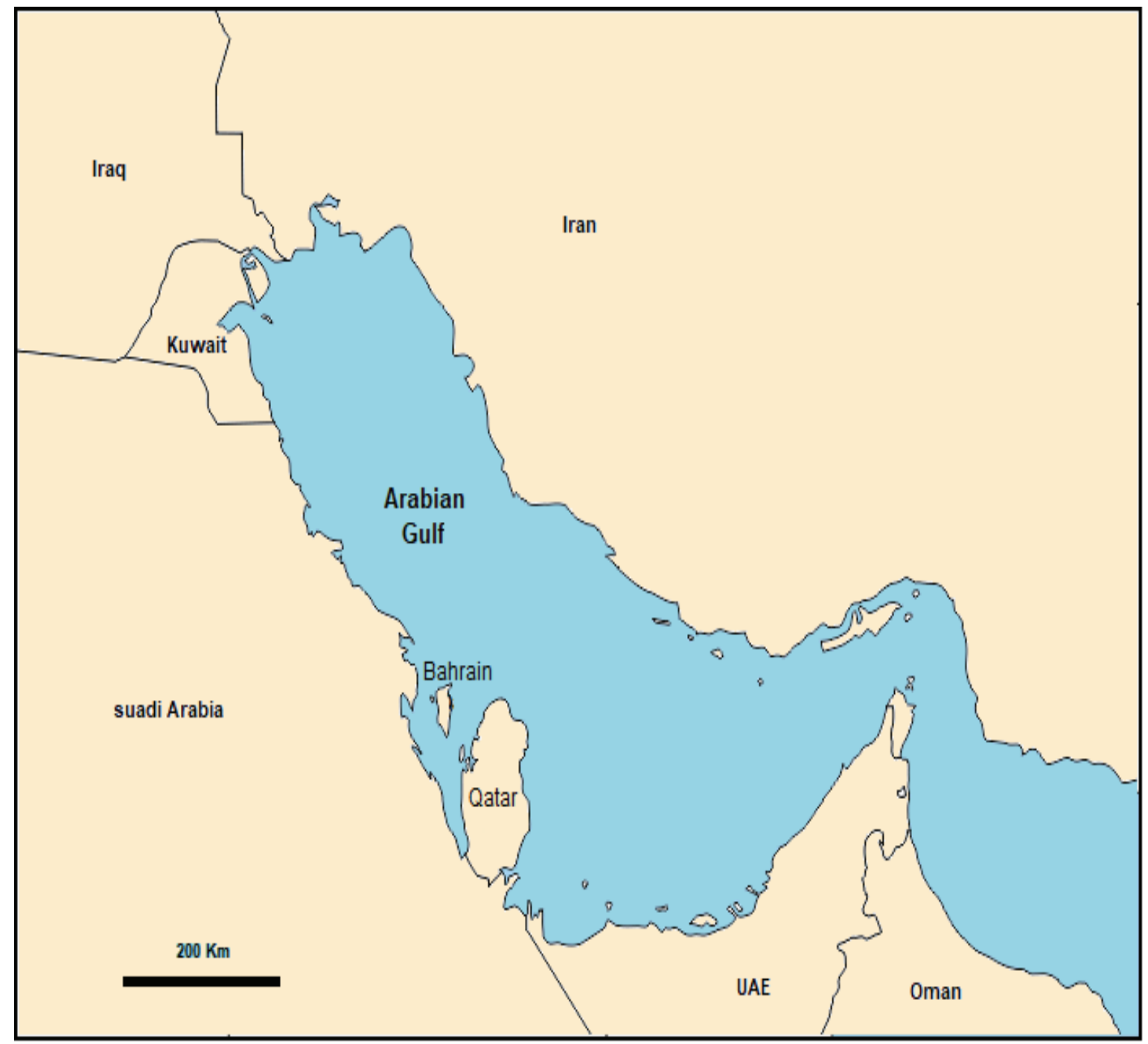

Figure 1. The study area (Arabian Gulf).

\section{Remote sensing data}

The data used in this study are downloaded from the OceanColor website (oceancolor.gsfc.nasa.gov). NASA OceanColor is a platform supported by the Ocean Biology Processing Group (OBPG) at NASA's Goddard Space Flight Center. Since 1996, NASA has provided the global scientific society with different marine products depending on satellite data. Moderate Resolution Imaging Spectroradiometer (MODIS) is a spectrometer aboard Terra (EOS AM-1) and Aqua (EOS PM-) satellites. Together, Terra and Aqua have a temporal resolution of 1 to 2 days. MODIS has a spectral resolution of 36 bands, ranging from 0.405 to $14.385 \mu \mathrm{m}$. The pixel size (spatial resolution) of MODIS 
images varies by the used band, ranging from 250 to 1000 square meters. Due to the high temporal resolution of MODIS, it helps us improve our understanding of global dynamics and processes on the earth. MODIS data comes in various levels. Levels 1 and 2 contain geometric and radiometric calibrated data with full-resolution, timereferenced and derived geophysical variables, such as chlorophyll- $a$ concentration. Level 3 data are the time-derived geophysical variables for a specific period (monthly, seasonally, etc.) (see Table 1) (Feldman, 2020). In this study, 64 Level 3 data points were measured from 2004 to 2019, and 11 Level 2 data points were used for temporal analysis and validation, respectively.

Table 1. MODIS properties for the study area.

\begin{tabular}{|c|c|}
\hline Spatial resolution & $250-1000 \mathrm{~m}$ \\
\hline Temporal resolution & $1-2$ days \\
\hline Spectral resolution & 36 bands \\
\hline Mission & 2 satellites (Aqua - Terra) \\
\hline Local capturing time & 11 AM -2 PM (GMT +3 ) \\
\hline Levels and products & Yes \\
\hline
\end{tabular}

\section{Field Data}

The used field data were referred from the Environmental Public Authority (KEPA) (epa.org.kw). KEPA started to monitor the marine water quality parameters in 1984, and in 2016, it established a monitoring system for Kuwait's marine environment based on floating stations (number $=15$ ) spread over the territorial waters of the nation (Fig. 2). The buoys take near-surface parameters every 10 minutes, so that the hourly average can be extracted. The monitoring parameters cover sea surface temperature, salinity, chlorophyll- $a$, turbidity, $\mathrm{pH}$ and dissolved oxygen, among others. The sensors are calibrated annually, according to NIST standards, and periodically serviced. The chlorophyll- $a$ records submitted by the 15 stations throughout 2017 (10-11 AM GMT+3) were used in this study. The purpose of using the field data is to evaluate the estimated accuracy of chlorophyll- $a$ values extracted by the satellite. 


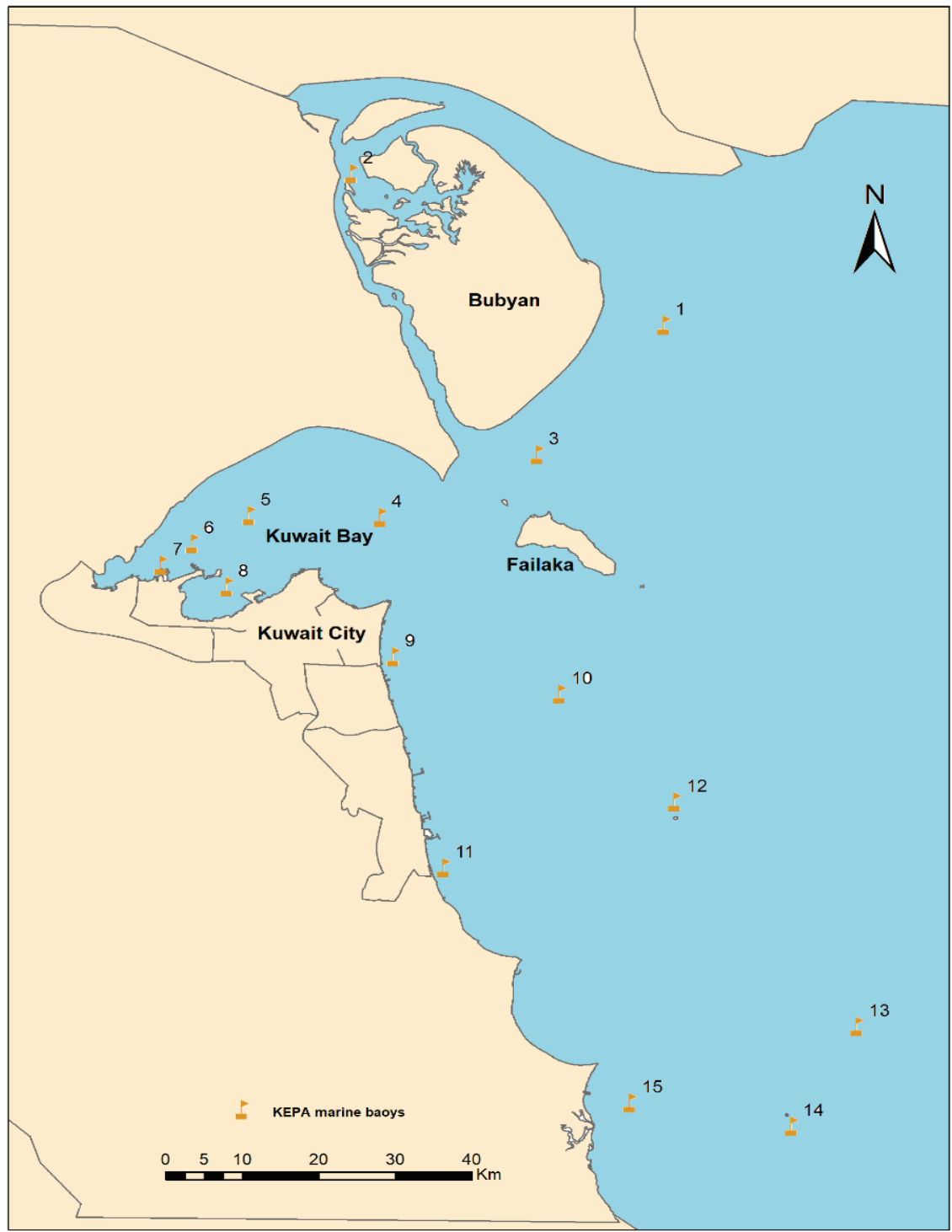

Fig. 2. The 15 buoy locations in Kuwaiti territorial water that were used in this study to validate MODIS data.

\section{Data Analysis and Validation}

The Level 3 chlorophyll- $a$ data were analysed using SeaDAS 7.5.3 software. The study area (the Arabian Gulf) was cropped to extract the statistical report. Then, the spatial mean and standard deviation were exported (Fig. 4). The spatial statistical measures are a geostatistical way of summarizing the values of a specific area. The spatial mean is the average of all the pixels values in the study area, while the standard deviation describes how the values deviate from the spatial mean; both can be used to show how chlorophyll- $a$ values change over the studied time. Following that, time series analysis was done for each season between 2004 and 2019 separately, and for all the seasons individually. 
To verify the accuracy of the estimated chlorophyll- $a$ values via MODIS, Level 2 data of MODIS spectrometer (11 images) were used to match the field data taken from KEPA floating stations (24 points) (Fig. 5). MODIS Level 2 is suitable for matching since its data are absolute values for specific days and not arithmetic averages or other statistical summaries. For comparison, a polygon covering 9 pixels of MODIS images was constructed around the sites of the floating stations. Then, the averages of these pixels were compared to the corresponding field values. The pixels' averages are then compared to avoid reliance on a single-pixel result, which may reflect an overestimated value (Albanai, 2019). This methodology has been previously applied in several studies (Albanai, 2020). Pixels with high standard deviation values were avoided in comparison for the sake of the accuracy of the analysis. Then, the root mean square error (RMSE) and the mean absolute error (MAE) were calculated to measure the accuracy of the MODIS chlorophyll- $a$ product. These statistical measures are used to compare two variables, and to estimate the difference between them, in terms of both absolute numbers and percentage (Albanai, 2021a, 2021b). The following equations were used to compute RMSE and MAE:

$R M S E= \pm \sqrt{\frac{1}{n} \sum_{i=1}\left(f_{i}-f_{j}\right)^{2}}$

$M A E=\frac{1}{n} \sum_{i=1}\left|f_{i}-f_{j}\right|$

where $f_{i}$ is the value of the chlorophyll- $a$ product, and $f_{j}$ is the field data value.

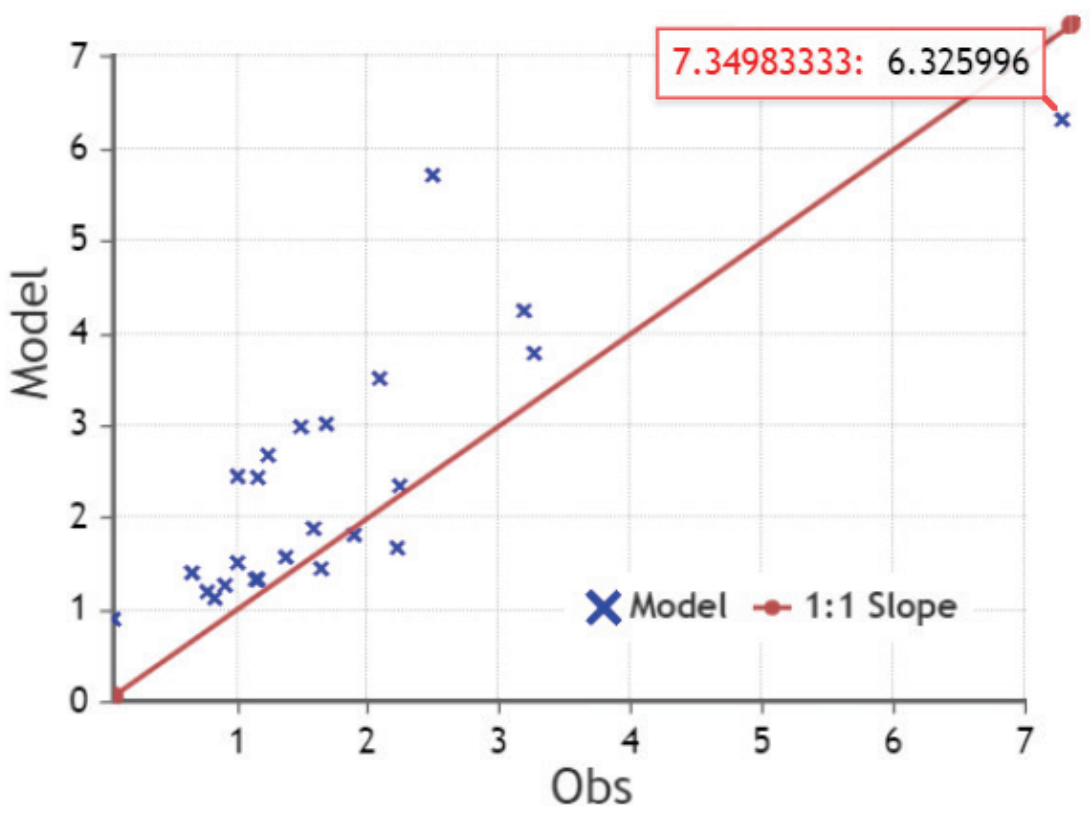

Figure 3. The VIIRS chlorophyll- $a$ level 2 product and the field data $\left(\mathrm{mg} . \mathrm{m}^{-3}\right)$ scattering plots indicates the correlation between the two variables. 


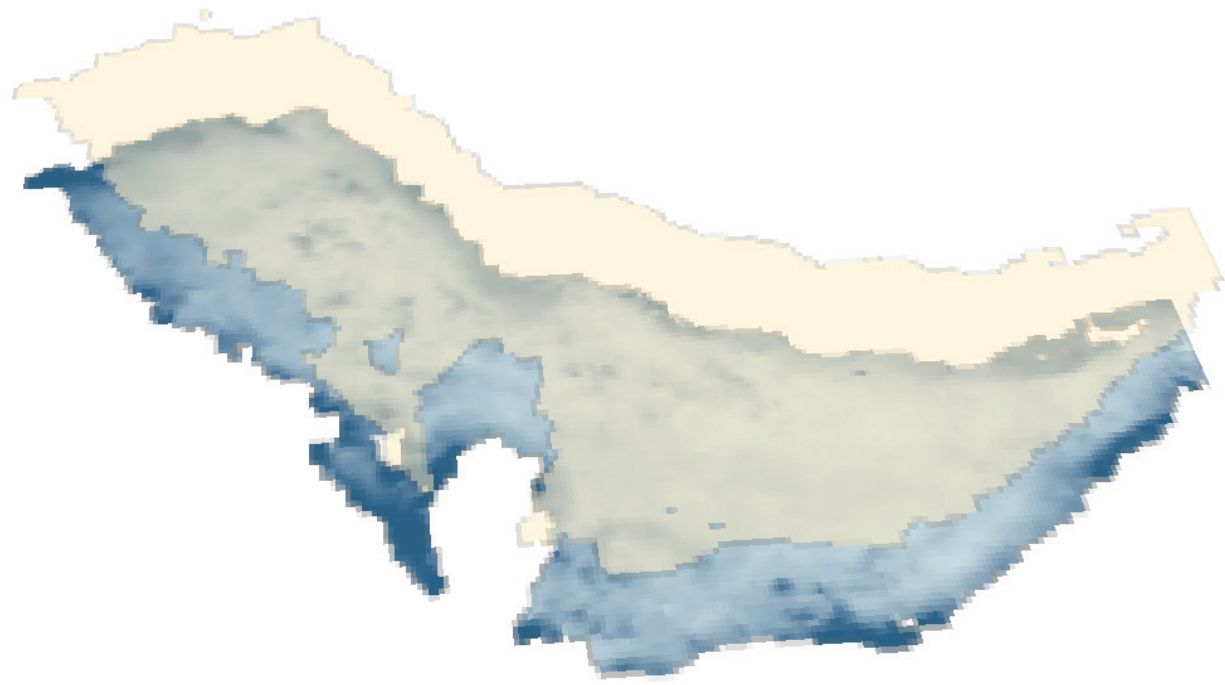

Figure 4. The spatial mean and standard deviation values were extracted for the whole area of the Arabian Gulf.

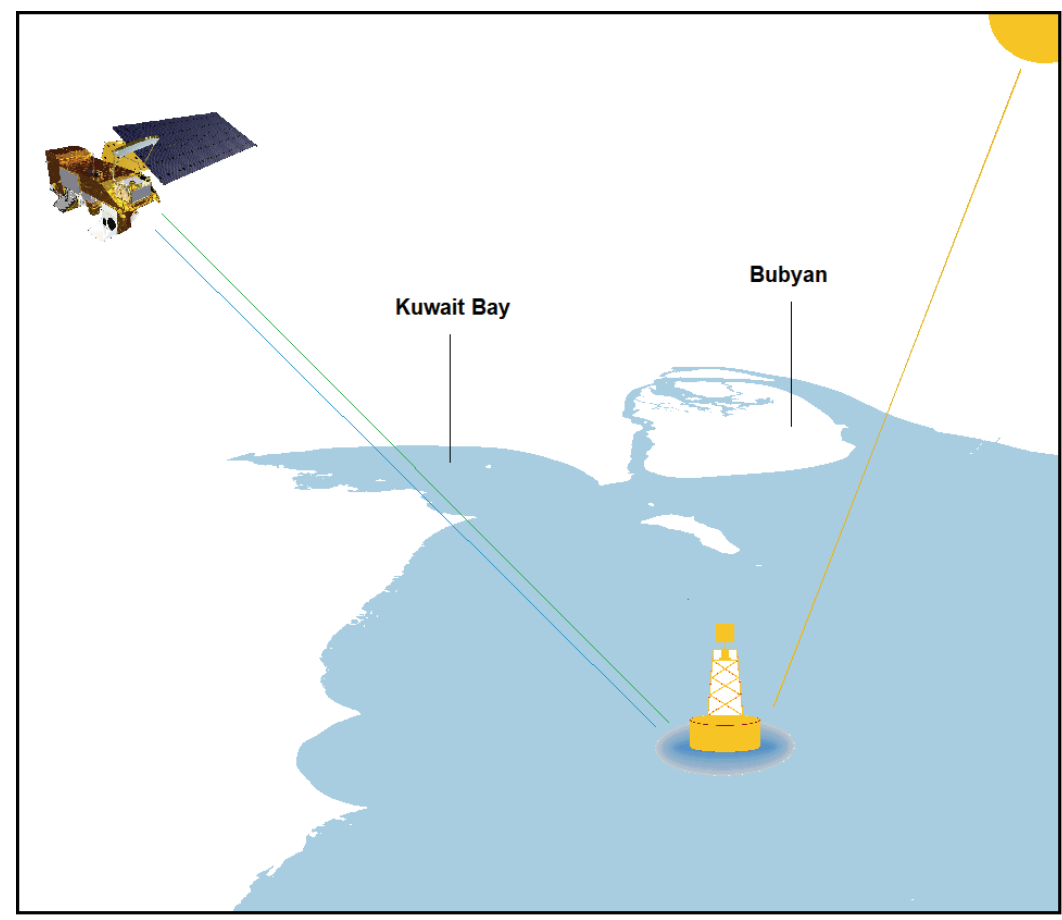

Figure 5. The process of comparing field data from Kuwaiti waters to satellite geophysical extracted data for the same geographical location. 


\section{RESULTS AND DISCUSSION}

The results of the temporal distribution analysis of chlorophyll- $a$ from 2004 to 2019 (over 16 years) showed that the concentration takes a semiregular annual cycle, which increases in winter and decreases in summer (Fig. 6). The results indicated that this cycle is prevalent in the Arab Gulf throughout the years included in the study. However, chlorophyll- $a$ concentration values deviate from the mean by 1.02 for summer, 0.99 for fall, 0.93 for winter, and 1.03 for spring $\left(\mathrm{mg} \cdot \mathrm{m}^{-3}\right)$ (mean deviation from 2004 to 2019). Also, the results showed that there are peaks in the seasonal averages of chlorophyll- $a$ concentration, perhaps the most important of which was observed in 2008, when the average chlorophyll- $a$ concentration in spring reached $3.09 \mathrm{mg} . \mathrm{m}^{-3}$. The rest of the peaks are semimoderated and regular with an average of $1.59 \mathrm{mg} . \mathrm{m}^{-3}$ (in spring). No sharp reductions in chlorophyll- $a$ concentration were reported, where the average chlorophyll- $a$ concentration reported in summer (bottom) was $1.05 \mathrm{mg} . \mathrm{m}^{-3}$. The average chlorophyll- $a$ concentration during the fall and winter was 1.18 and $1.59 \mathrm{mg} . \mathrm{m}^{-3}$, respectively. Trend analysis showed that the chlorophyll- $a$ concentration was declining from 2004 to 2019 by about $0.7 \mathrm{mg} . \mathrm{m}^{-3}$. The results show that the decline is observed in the averages for all seasons, and the decrease was most pronounced during fall and winter (Fig. 7 and Fig. 9). We note that the 2008 peak was very clear in the trend during spring, to a lesser degree for both summer (Fig. 10) and winter (Fig. 8), and was relatively clear in fall (Fig. 7).

The results of investigating the accuracy of chlorophyll- $a$ product for MODIS using field data monitored through KEPA floating monitoring stations indicated that there is a positive correlation between the two variables $\left(r^{2}=\right.$ 0.6649). This relationship was reflected in the observed statistical measures (Table 2.).

Satellite data increase our understanding of ocean dynamics and the temporal changes that occur. However, this does not mean that the analysis is free from some restrictions that may reduce its accuracy. Reilly et al. (2000) explained that the values of satellite sensors are affected by seabed reflections in shallow areas, and this is one of the most prominent features of the Arab Gulf. However, the spatial coverage of the moderate resolution satellite sensors weakens for marginal seas such as the Arabian Gulf, and this was evident when analyzing MODIS data, as coverage on narrow coasts and waterways is relatively limited. Also, the missing data noticed in summer seasons must be taken into consideration, due to the impediment of dust storms when monitoring concentration from space.

The drop in chlorophyll- $a$ concentration in fall is often due to depleted nutrients by the phytoplankton bloom in winter (Al-Naimi et al., 2017). Previous research by Nezlin et al. (2007) clearly shows that the seasonal cycles of chlorophyll- $a$ concentration in tropical and subtropical oceans are typical. This is because the phytoplankton growth is affected by the low nutrient concentration, because of the strong pycnocline formation, in addition to the effects of thermal stratification in the water column; all of this limits the vertical mixing, so that the nutrients can rise to the surface (Doney, 2006). This study result is consistent with other studies regarding the seasonal changes (Al-Naimi et al., 2017; Zhang, Jiang, Chen, Zhang, \& Wang, 2012; Zhao \& Ghedira, 2014).

The validation results of the product showed better accuracy to monitor low-concentration waters, while the accuracy in high-concentration waters decreases. Reviewing the extracted chlorophyll- $a$ concentration using different equations and the OceanColor satellite sensors for several seas and different bays around the world, with different numbers of GTPs (30-114), we find that the accuracy varied in some literature from 0.18 to $0.64 \mathrm{mg} \cdot \mathrm{m}^{-3}$ (Al-Yamani \& Naqvi, 2019; Husar, Prospero, \& Stowe, 1997; Johns, Yao, \& Olson, 2003; Polikarpov, Saburova, \& Al-Yamani, 2016). The accuracy was estimated at $0.23 \mathrm{mg} / \mathrm{m}^{-3}$ in the middle of the Arabian Gulf using 29 GTPs (Al-Naimi et al., 2017), and thus the accuracy of the product falls within a reasonable range, especially in a difficult environment such as the north-west corner of the Arabian Gulf.

The observed increase in chlorophyll- $a$ concentration in 2008 was due to an extensive bloom of ichthyotoxic dinoflagellate Cochlodinium polykrikoides in the Arabian Gulf, the Strait of Hormuz, and the Gulf of Oman. The bloom was notable for its unusual coverage, intensity, and duration from August 2008 through May 2009. It caused 
large numbers of fish kill and coral reefs damage, restricted fishing activities, and forced desalination plants in the Arabian Gulf. Harmful Algal Blooms (HABs) and fish kills are relatively new phenomena (linked to climate change and anthropogenic activities) in the area except the sporadic red tide caused by some harmless species of plankton (Polikarpov, Al-Yamani, \& Saburova, 2019). However, a significant increase in nutrients has been identified, caused chiefly by the sewage discharge from the urban coastal areas along the coasts of the Gulf (Al-Yamani \& Naqvi, 2019). Recently, anthropogenic stresses have been cited as one of the biggest challenges facing the marine ecological environment of the Arabian Gulf besides climate change. Climate change affects the sea surface temperature and hence the concentration of dissolved oxygen, which represents one of the most important challenges for an extreme environment such as the Arabian Gulf. Additionally, Al-Yamani and Naqvi (2019) study showed that salinity has increased in the northern area of the Gulf because of the reduction of river runoff, which may be one of the most observed changes by both climate change and anthropogenic activities.

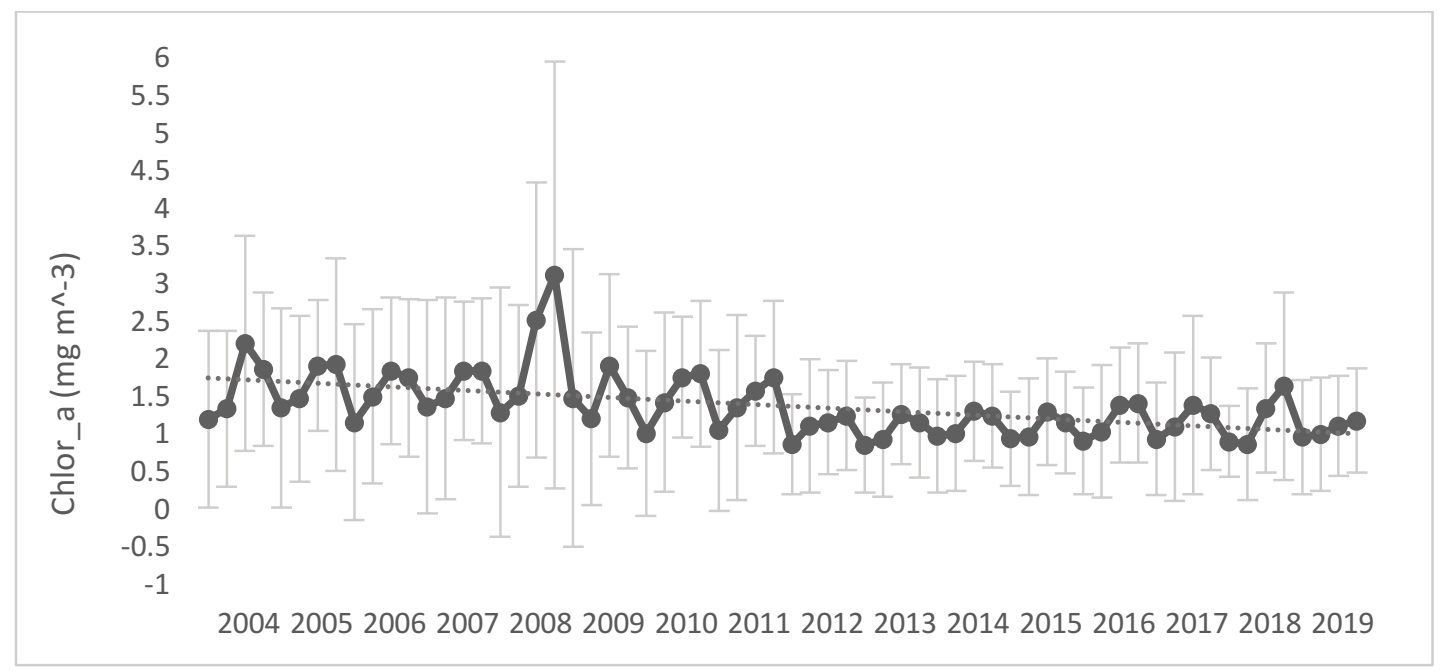

Figure 6. The overall trend from 2004 to 2019.

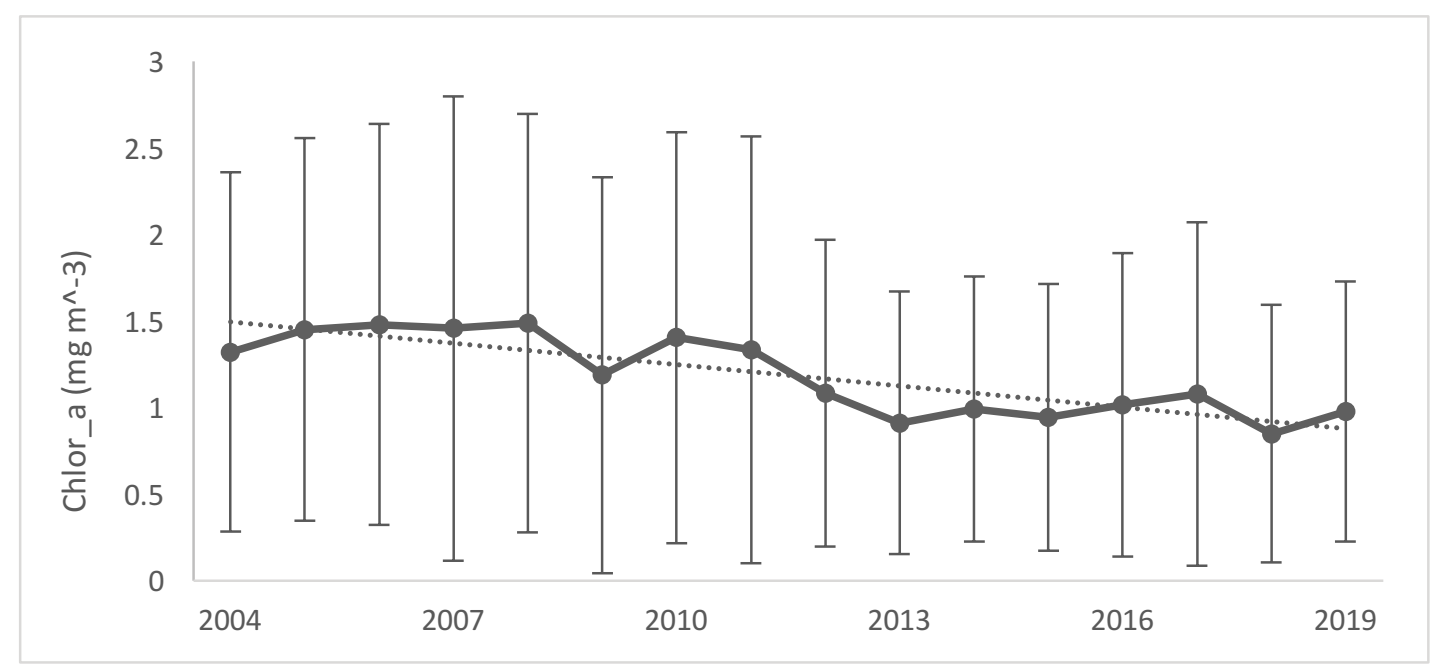

Figure 7. The fall trend from 2004 to 2019. 


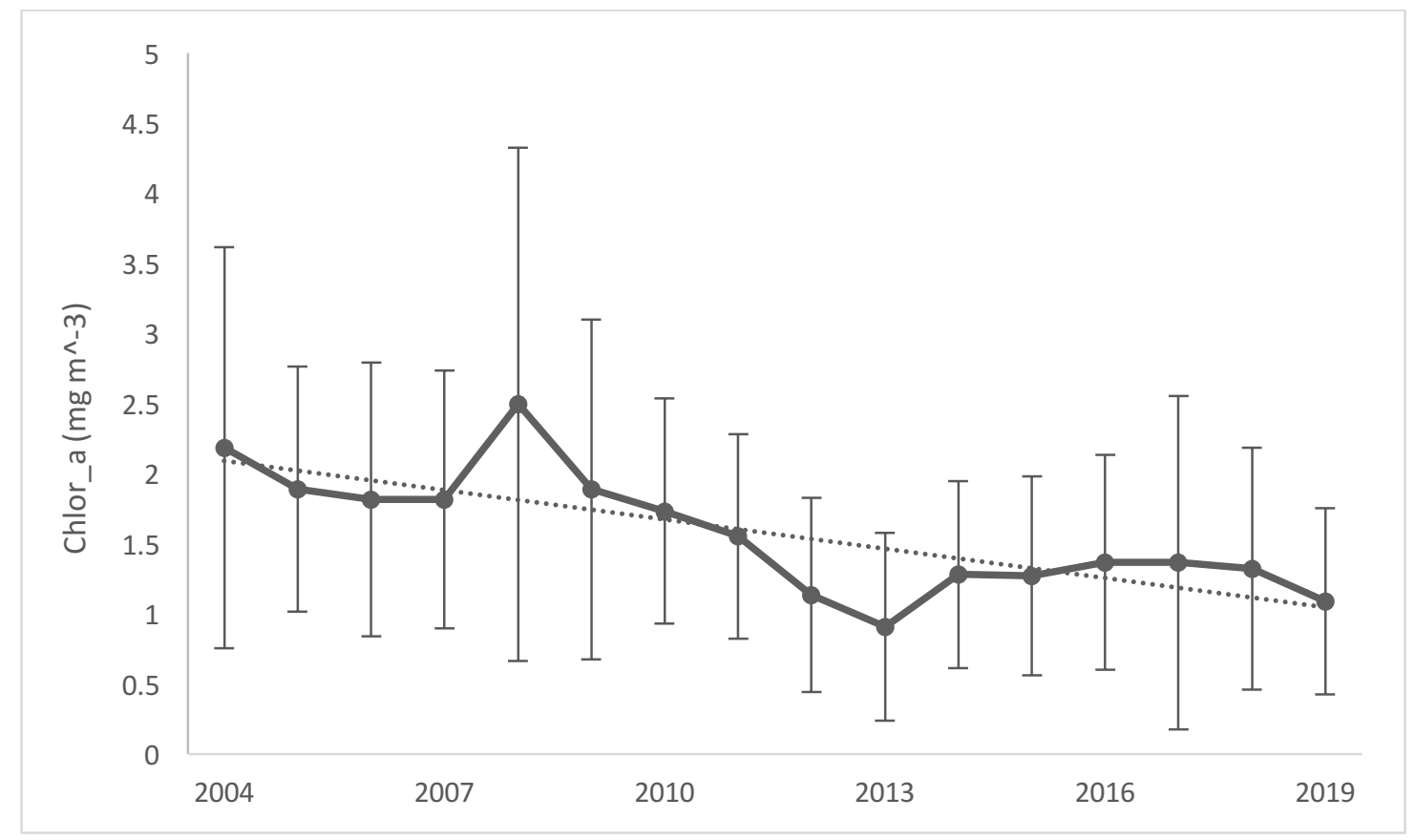

Figure 8. The winter trend from 2004 to 2019.

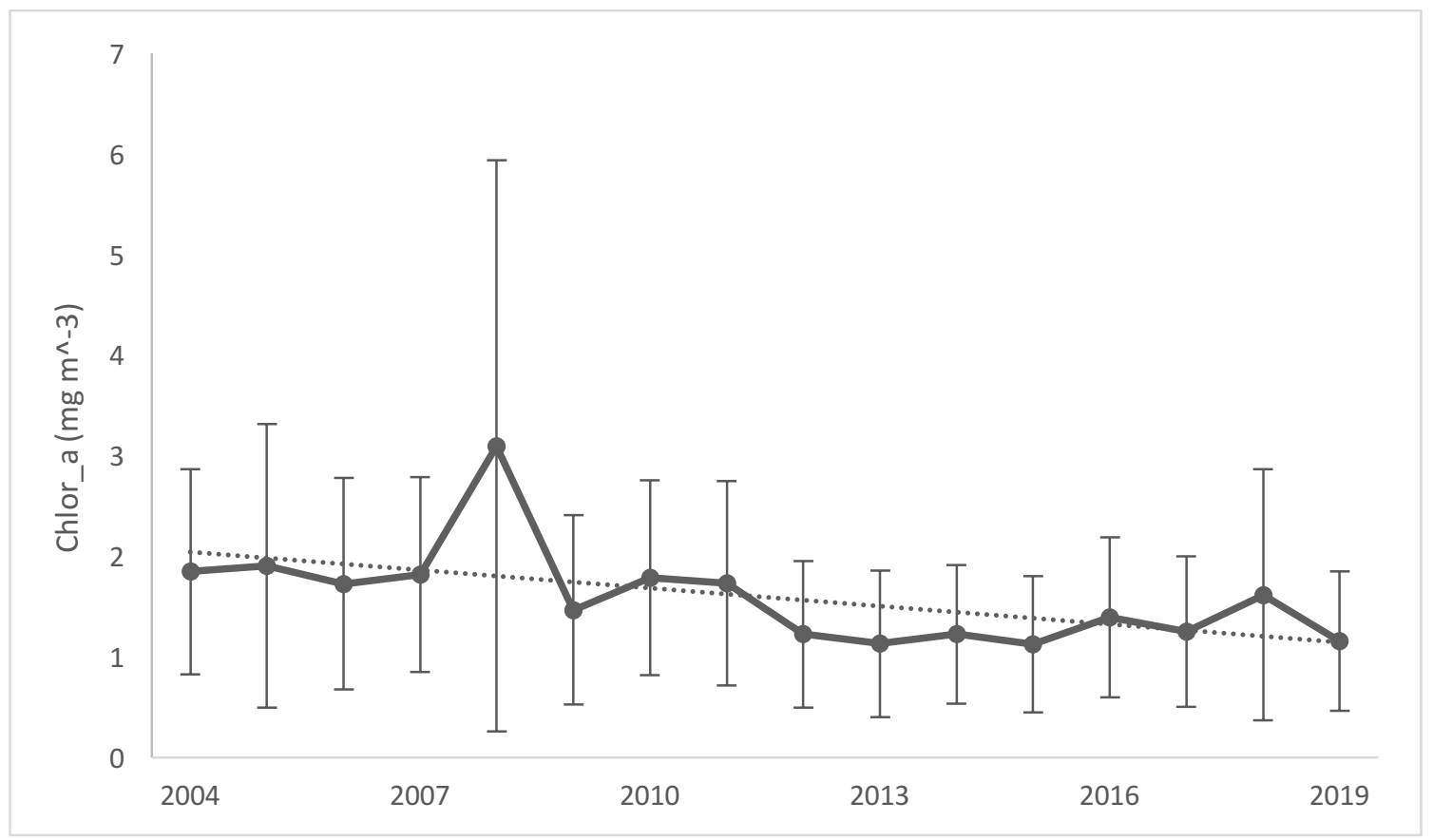

Figure 9. The spring trend from 2004 to 2019. 


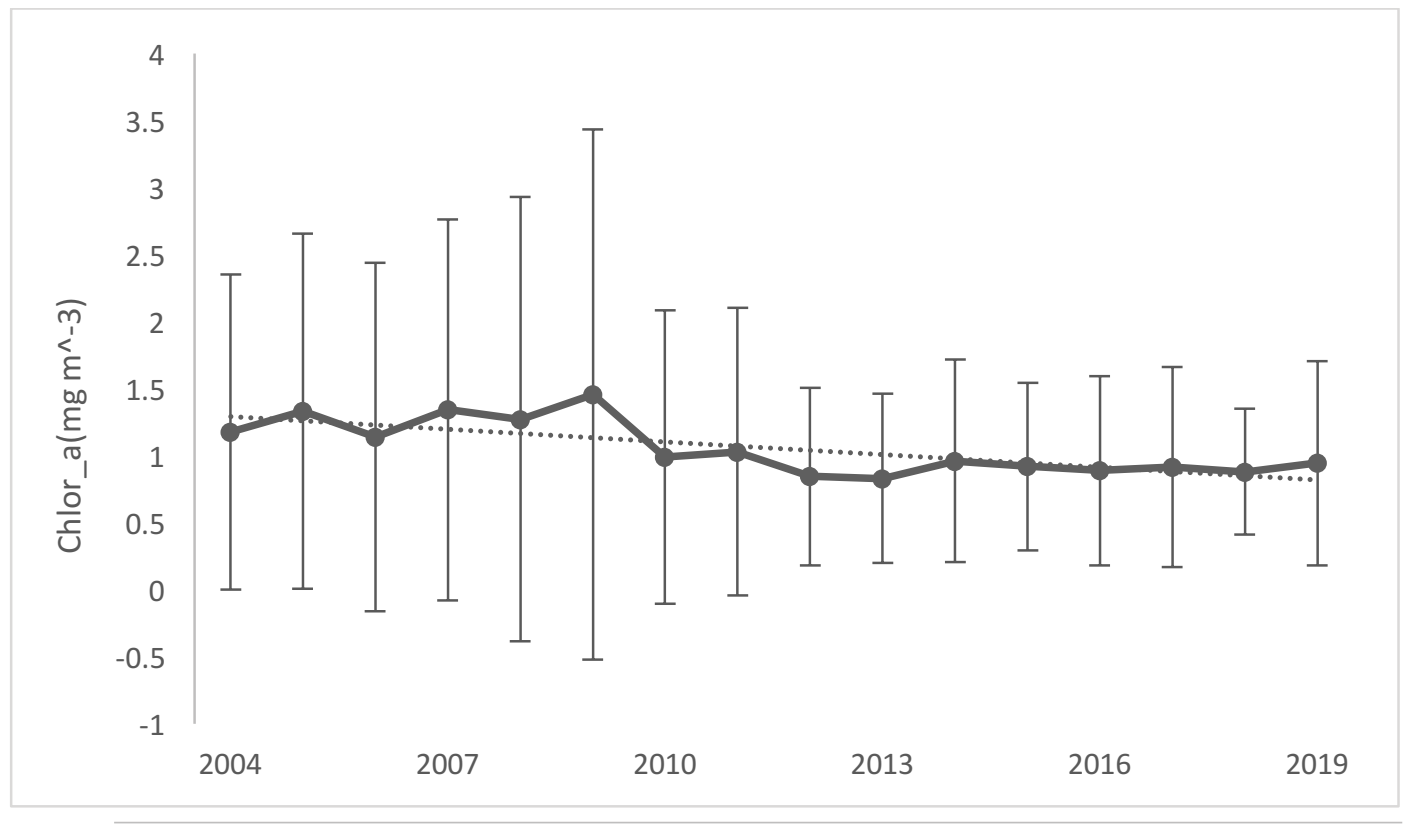

Figure 10. The summer trend from 2004 to 2019.

Table 2. RMSE, MAE, MAPE and $r^{2}$ scores.

\begin{tabular}{|c|c|}
\hline$R M S E$ & 1.066 \\
\hline$M A E$ & 0.802 \\
\hline$r^{2}$ & 0.6649 \\
\hline
\end{tabular}

\section{CONCLUSION}

In this study, the MODIS (Aqua) Levels 2 and 3 data were used to extract the spatial mean and the seasonal standard deviation from 2004 to 2019 (across 16 years) for the Arab Gulf, and to estimate the accuracy of MODIS values by matching the MODIS data to the field data taken from KEPA monitoring floating stations. The results showed a good accuracy of the sensor data $(\mathrm{RMSE}= \pm 1.066)$, and they indicated that the temporal average gradually decreased by about $0.7 \mathrm{mg} / \mathrm{m}^{-3}$ from 2004 to 2019 . The study recommends relying on satellites with higherspecification properties to understand the spatial and temporal distribution of chlorophyll. It also recommends relying on field measurements taken from different regions of the Arabian Gulf as a whole, in addition to building an empirical model to estimate chlorophyll- $a$ concentration in the Gulf.

\section{ACKNOWLEDGMENT}

The author would like to thank the Kuwait Environmental Public Authority (KEPA), especially eMISK, and the marine monitoring section. Also, acknowledgments must go to NASA for making available the MODIS imagery. 


\section{REFERENCES}

Al-Naimi, N., Raitsos, D. E., Ben-Hamadou, R., \& Soliman, Y. (2017). Evaluation of Satellite Retrievals of Chlorophyll- a in the Arabian Gulf, 301(10), 1-13. https://doi.org/10.3390/rs9030301

Al-Yamani, F., \& Naqvi, S. W. A. (2019). Chemical oceanography of the Arabian Gulf. Deep Sea Research Part II: Topical Studies in Oceanography, 161, 72-80. https://doi.org/https://doi.org/10.1016/j.dsr2.2018.10.003

Al-Yamani, F., Saburova, M., \& Polikarpov, I. (2012). A preliminary assessment of harmful algal blooms in Kuwait's marine environment. Aquatic Ecosystem Health \& Management, 15(sup1), 64-72. https://doi.org/10.1080/14634988.2012.679450

Al-Yamani, F., Bishop, J., Ramadhan, E., Al-Husaini, M., \& Al-Ghadban, A. (2004). Oceanographic Atlas of Kuwait's waters (1st ed.). Kuwait: Kuwait Istituite for Scientific Research.

Albanai, J. A. (2019). A GIS Science Simulation for the Expected Sea Level Rise Scenarios on Failka Island in The State of Kuwait (1st ed.). Kuwait: Center For Research and Studies on Kuwait.

Albanai, J. A. (2020). Sea Level Rise Projections for Failaka Island in The State of Kuwait. Transaction on Maritime Science, 9(2), 236 - 247. https://doi.org/10.7225/toms.v09.n02.008.

Albanai, J. A. (2021a). Mapping Kuwait bathymetry using passive multispectral remote sensing. Kuwait Journal of Science.

Albanai, J. A. (2021b). Spatial Distribution of Kuwait Coastal Geomorphological Features using Remote Sensing Methods and GIS Soultions. Journal of Social Sciences.

Brewer, P. G., \& Dyrssen, D. (1985). Chemical Oceanography of the Persian Gulf. Prog. Oeeanog, 14(5529), $41-55$.

Doney, S. C. (2006). Plankton in a warmer world. Nature, 444(7120), 695-696. https://doi.org/10.1038/444695a

Feldman, G. C. (2020). Chlorophyll a (chlor_a). Retrieved September 30, 2020, from https://oceancolor.gsfc.nasa.gov/atbd/chlor_a/

Husar, R. B., Prospero, M., \& Stowe, L. L. (1997). Characterization of tropospheric aerosols over the oceans with the NOAA advanced very high resolution radiometer optical thickness operational product. JOURNAL QF GEOPHYSICAL RESEARCH, 102(D14), 16889-16909.

Johns, W. E., Yao, F., \& Olson, D. B. (2003). Observations of seasonal exchange through the Straits of Hormuz and the inferred heat and freshwater budgets of the Persian Gulf. Journal of Geophysical Research, 108(C12), 3391. https://doi.org/10.1029/2003JC001881

Moradi, M., \& Kabiri, K. (2015). Spatio-temporal variability of SST and Chlorophyll-a from MODIS data in the Persian Gulf. Marine Pollution Bulletin, 98(1-2), 14-25.

https://doi.org/10.1016/j.marpolbul.2015.07.018

Muller-Karger, F. E., Hu, C., Andréfouët, S., Varela, R., \& Thunell, R. (2005). The Color of the Coastal Ocean and Applications in the Solution of Research and Management Problems. In R. L. Miller, C. E. Del Castillo, \& B. A. Mckee (Eds.), Remote Sensing of Coastal Aquatic Environments: Technologies, Techniques and Applications (pp. 101-127). Dordrecht: Springer Netherlands. https://doi.org/10.1007/9781-4020-3100-7_5

Nezlin, N. P., Polikarpov, I. G., \& Al-yamani, F. (2007). Satellite-measured chlorophyll distribution in the Arabian Gulf: Spatial, seasonal and inter-annual variability. International Journal of Oceans and Oceanography, 2(1), 139-156. Retrieved from https://scholar.google.com/scholar_lookup?title=Satellitemeasured chlorophyll distribution in the Arabian Gulf\%3A Spatial\%2C seasonal and inter-annual variability\&author=N.P. Nezlin\&publication_year $=2007$ 
Nezlin, N. P., Polikarpov, I. G., Al-Yamani, F. Y., Subba Rao, D. V, \& Ignatov, A. M. (2010). Satellite monitoring of climatic factors regulating phytoplankton variability in the Arabian (Persian) Gulf. Journal of Marine Systems, 82(1), 47-60. https://doi.org/https://doi.org/10.1016/j.jmarsys.2010.03.003

Pokavanich, T., Alosairi, Y., Graaff, R. de, Morelissen, R., Verbruggen, W., Al-Refail, K., ... Al-Said, T. (2014). THREE-DIMENSIONAL HYDRO-ENVIRONMENT CHARACTERIZATION AND MODELING OF THE NORTHERN ARABIAN GULF. Coastal Engineering Proceedings, (2014). https://doi.org/10.9753/icce.v34.management.41

Polikarpov, I., Al-yamani, F., \& Saburova, M. (2019). Remote Sensing of Phytoplankton Variability in the Arabian / Persian Gulf. In V. Barale \& M. Gade (Eds.), Remote Sensing of the Asian Seas (pp. 485-501). Springer. https://doi.org/10.1007/978-3-319-94067-0

Polikarpov, I., Saburova, M., \& Al-Yamani, F. (2016). Diversity and distribution of winter phytoplankton in the Arabian Gulf and the Sea of Oman. Continental Shelf Research, 119, 85-99. https://doi.org/https://doi.org/10.1016/j.csr.2016.03.009

Reilly, J., O’Brien, M., Siegel, D., Toole, D., Menzies, D., Smith, R., ... Culver, M. (2000). SeaWiFS Postlaunch Calibration and Validation Analyses, Part 3. (S. Hooker \& E. Firestone, Eds.) (Vol. 11).

Reynolds, R. M. (1993). Physical oceanography of the Gulf, Strait of Hormuz, and the Gulf of Oman-Results from the Mt Mitchell expedition. Marine Pollution Bulletin, 27(August), 35-59. Retrieved from https://scholar.google.com/scholar?hl=en\&as_sdt=0\%2C $5 \& \mathrm{q}=$ Physical + oceanography + of + the + Gulf $\% 2 \mathrm{C}+$ Strait + of + Hormuz $\% 2 \mathrm{C}+$ and + the + Gulf + of + Oman +results + from + the + Mt. + Mitchell+expedition. + Mar+Pollut + Bull $+27 \% 3 \mathrm{~A} 35-59 \& b t n G=$

Sheppard, C., Al-husiani, M., Al-jamali, F., Al-yamani, F., Baldwin, R., Bishop, J., ... Zainal, K. (2010). The Persian / Arabian Gulf: a young sea in decline . Mar Pollut Bull The Gulf: A young sea in decline q. Marine Pollution Bulletin, 60(1), 13-38. https://doi.org/10.1016/j.marpolbul.2009.10.017

Zhang, Y., Jiang, H., Chen, C., Zhang, X. Y., \& Wang, Y. (2012). Wavelet analysis on chlorophyll concentration change in the area around Bohai Bay area, Yangtze River Delta Region and South China Sea. Procedia Environmental Sciences, 13, 1373-1382. https://doi.org/https://doi.org/10.1016/j.proenv.2012.01.130

Zhao, J., \& Ghedira, H. (2014). Monitoring red tide with satellite imagery and numerical models: A case study in the Arabian Gulf. Marine Pollution Bulletin, 79(1), 305-313. https://doi.org/https://doi.org/10.1016/j.marpolbul.2013.10.057 